Article

\title{
Farmers' Adoption Preferences for Sustainable Agriculture Practices in Northwest China
}

\author{
Yixin Nong ${ }^{1}$, Changbin Yin ${ }^{2} \mathbb{D}$, Xiaoyan $\mathrm{Yi}^{2}{ }^{2}$, Jing Ren ${ }^{2}$ and Hsiaoping Chien ${ }^{3, * \mathbb{C}}$ \\ 1 Graduate School of Agricultural and Life Sciences, The University of Tokyo, 1-1-1 Yayoi, Bunkyo-Ku, \\ Tokyo 113-8657, Japan; nongyixin649@g.ecc.u-tokyo.ac.jp \\ 2 Institute of Agricultural Resources and Regional Planning, Chinese Academy of Agricultural Sciences, \\ Beijing 100081, China; yinchangbin@caas.cn (C.Y.); yixiaoyan@caas.cn (X.Y.); renjing@caas.cn (J.R.) \\ 3 Japan International Research Center for Agricultural Sciences, 1-1 Ohwashi, Tsukuba, Ibaraki 305-8686, Japan \\ * Correspondence: chienp@affrc.go.jp; Tel.: +81-29-838-6350
}

Received: 10 July 2020; Accepted: 3 August 2020; Published: 4 August 2020

check for updates

\begin{abstract}
In the highest soil erosion regions of arid and semiarid northwest China, water resource deficits and farmland misuse have further exacerbated soil degradation. Therefore, understanding how farmers in diverse agroclimatic zones perceive and respond to different conservation practices is important to the implementation of sustainable agriculture practices (SAPs). To this end, this study uses a best-worst scaling approach to examine the adoption preferences for nine SAPs among grain and cash crop farmers and investigates the influence of farm and climatic characteristics on adoption preferences based on a face to face survey of 554 households in Gansu province, which is classified as an arid and semiarid area in northwest China. Both grain and cash crop farmers had stronger preferences for the practices of using organic instead of chemical fertilizers and of improving irrigation practices. In addition, while cash crop farmers also had strong preferences for cover crop-related practices, they preferred long-term fallows least. Household income, livestock, and precipitation influence the potential perceived importance of SAPs. The different perceived importance of these practices suggests new possible combinations or packages for a sustainable agriculture program during the cropping structure adjustment in Gansu.
\end{abstract}

Keywords: adoption preference; sustainable agriculture practices; best-worst scaling; northwest China

\section{Introduction}

Soil degradation causes the loss of the actual and potential productivity of soil, the deterioration of vegetative cover, and the decline of soil and water resources, which are major threats to agricultural sustainability and environmental quality [1]. Among the high soil erosion regions in arid and semiarid regions, human intervention and farmland misuse, including removing natural vegetation, applying excessive agrochemicals, degrading marginal lands, and over-exploiting the vegetation, have exacerbated soil degradation [2]. As such, for many arid or semiarid South and Central Asian and African countries, implementing sustainable agriculture practices (SAPs) to restore soil quality and mitigate degradation is essential for agricultural sustainability and food security.

In China, one-half of the land area is arid or semiarid and $26.6 \%$ has an average precipitation below $200 \mathrm{~mm}$ per year [3]. Gansu province is a representative area of the arid and semiarid climate and fragile ecological environment in northwest China. Traditional crop production practices involve intensive cultivation by ploughing and harrowing soil two to three times between harvest and spring sowing, while crop stubbles and residues are usually removed from the field for forage or fuel use [4]. The sparse vegetation soil cover and seasonal rainfall decrease the structural instability and production 
potential of the soil in this province. Furthermore, Gansu is one of the poorest provinces and is home to $40 \%$ [2] of the rural poor in China [5]. To achieve environmental protection and poverty reduction, the Chinese government has invested heavily in ecological restoration and conservation programs (e.g., Three Norths Shelter Project, Grain for Green Project, Gully Land Consolidation Project), while also campaigning to increase the production of cash crops to reduce the reliance on grain production [6]. As a result, according to the provincial census data, the wheat sown area decreased from $23.76 \%$ to $20.50 \%$ of the total arable land and the cash crops of vegetables, fruits, and traditional Chinese herbs were sown on $15.07 \%$ of the total arable land in 2017, as opposed to $10.55 \%$ in 2010 [7]. During these transitions, understanding how farmers in diverse agroclimatic zones perceive and respond to different conservation practices is important for policymakers to determine the favorable SAPs and what related policies should be designed.

Although introducing SAPs to promote long-term soil fertility and productivity, along with minimizing water use and lowering pollution levels at the farm level, bring profound changes in farm management, the results from adopting SAPs by farms has been limited, despite the extensive research and policy implementation investments $[2,8,9]$. On one hand, SAPs are only favorable to certain farmers in certain areas, implying the importance of recognizing the diverse resource endowments and farming systems at the farm and field levels $[4,10]$. On the other hand, some practices better fit certain farming systems and are approved by farmers, raising questions regarding which SAPs are more preferred by farmers and how they fit within current farming systems [9,11].

Thus far, aside from the engineering techniques of check dams and terraces regularly arranged by the government, the success of adopting SAPs, such as fertilizer technologies, alternative rotation of cover crops, conservation tillage (e.g., fallow or minimum tillage), and straw mulching, have mostly depended on farmers' willingness to adopt them, rather than being enforced by the government [6]. While extant studies employing farmers' adoption preferences have thus far provided useful information on the determinants of the adoption of various conservation practices, namely demographics [12], perception and awareness [13], and current practices [14], few studies have focused on planting differences and climatic features, which directly affect farmers' self-sufficiency, agricultural production, and subsequent income [2,13]. This study thus focuses on the adoption preferences for SAPs by grain and cash crop farmers in the arid and semiarid northwest China.

Aiming to investigate farmers' preferences for the adoption of SAPs within the context of planting structural adjustments, this study first assesses grain and cash crop farmers' perceived importance of potential SAPs; and second, it improves the understanding for the farm and climate characteristics underlying farmers' preferences regarding the adjustment of cropping structures. Our paper intends to enhance the current discussion on farm management and the adoption of SAPs, which is essential for agricultural sustainability and food security in arid and semiarid impoverished areas.

\section{Materials and Methods}

\subsection{Study Site}

Gansu province $\left(32^{\circ} 31^{\prime}-42^{\circ} 57^{\prime} \mathrm{N}\right.$ and $\left.92^{\circ} 13^{\prime}-108^{\circ} 46^{\prime} \mathrm{E}\right)$ lies at the conjunction of Loess Plateau, Qinghai-Tibetan Plateau, and Mongolia Plateau in inland northwestern China (Figure 1). The topography of Gansu is diverse, including mountains, plateaus, plains, river valleys, desert areas, and the Gobi desert [15]. The climate ranges from cold and arid, with a mean annual rainfall of $40 \mathrm{~mm}$ in the northwest, to a continental monsoon-influenced, semiarid climate with an annual rainfall of $600 \mathrm{~mm}$ in the southeast [16]. 


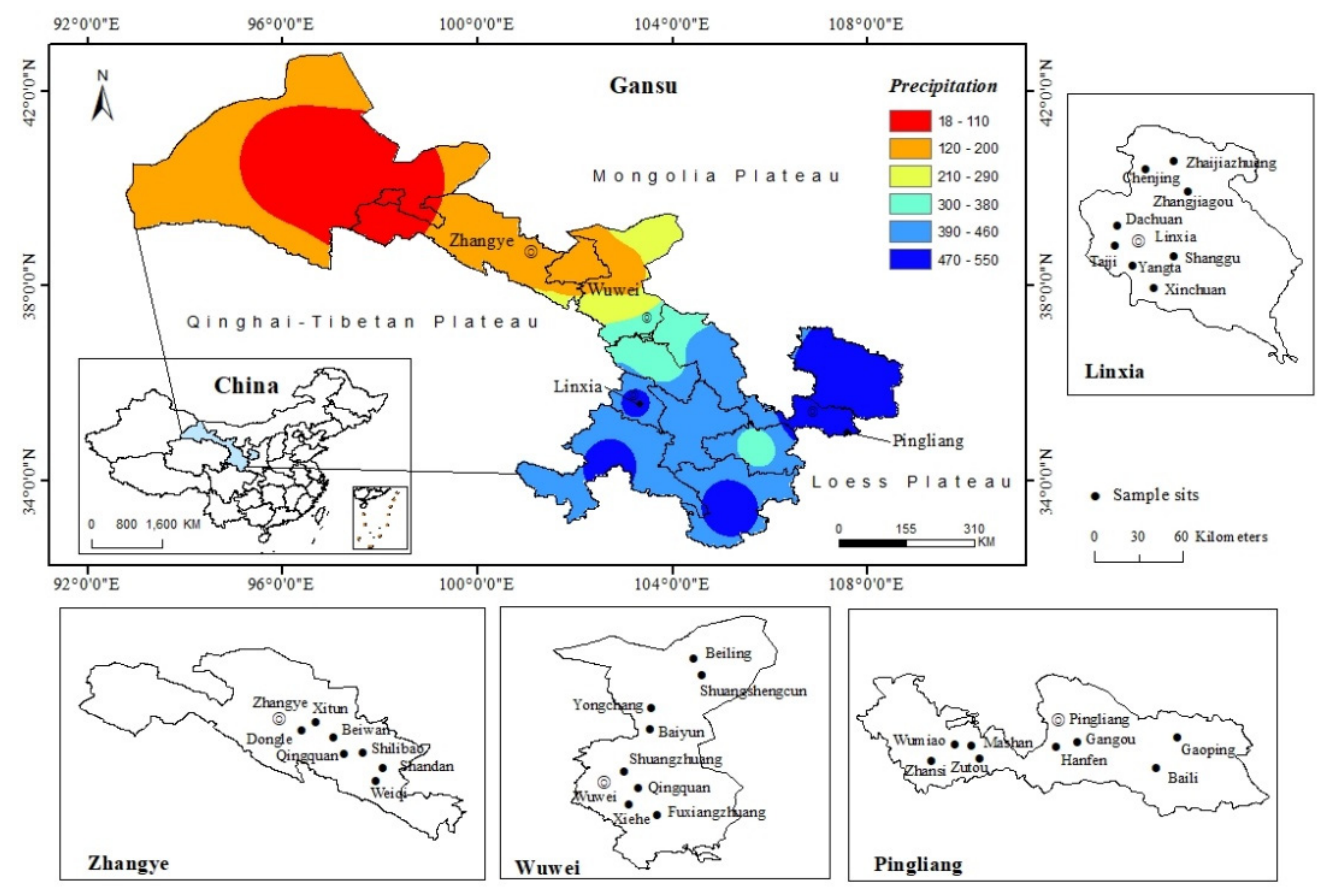

Figure 1. The geographical locations of sample areas: Zhangye, Wuwei, Linxia, and Pingliang.

The four districts of Zhangye, Wuwei, Linxia, and Pingliang were selected to provide an overview of the diverse geographic and climatic characteristics of Gansu. Zhangye and Wuwei are on the northwestern side, with average precipitation of $131 \mathrm{~mm}$ and $165 \mathrm{~mm}$ per year, while Linxia and Pingliang are on the southeast Gansu, with average precipitation of $492 \mathrm{~mm}$ and $532 \mathrm{~mm}$ per year, respectively (Figure 2). These regions experience hot, wet summers when rain falls concentratedly from July to September and long, dry winters with little rainfall. A combination of topographical features and water resources deficit lead to limited cultivated land with low soil fertility in terms of the agricultural production in Gansu. Despite having been equipped with basic irrigation systems, the entire region is still facing severe water shortage problems and crop water requirements can be barely met in northwest Gansu [17]. Based on the survey, farmland is irrigated once in a year in Zhangye, one to two times in Wuwei and, in the southern districts of Gansu, more frequent irrigation is provided in Linxia and Pingliang.

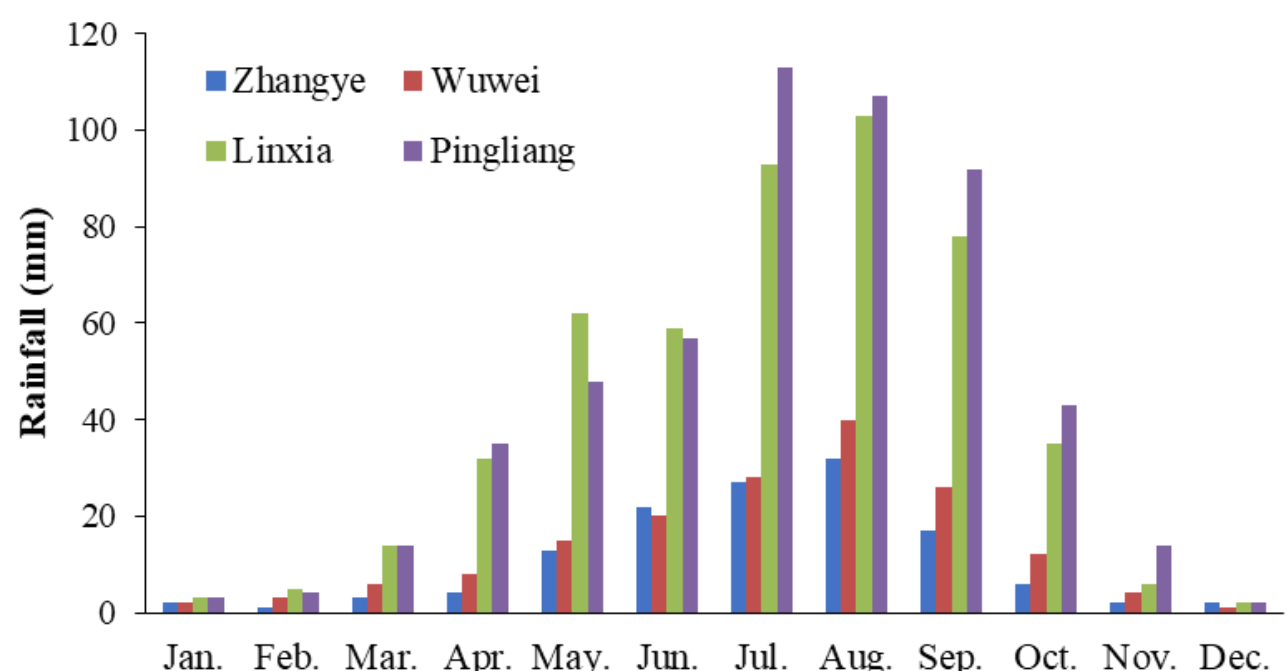

Figure 2. Average monthly rainfall (mm) of the four districts (1982-2012). Data obtained from the Gansu Meteorological Bureau. 


\subsection{Data Collection}

A pre-survey was conducted to determine farmers' understanding of the questions and how long they needed to complete the questionnaire. Based on the preliminary results, we revised the questionnaire and shortened the questions to ensure a higher response rate. We conducted face to face surveys from May to June 2019. Zhangye (seven villages), Wuwei (eight villages), Linxia (eight villages), and Pingliang (eight villages) were selected as sample sites (Figure 1). We randomly selected 616 households with 2553 residents from 31 villages for interviews $(0.68 \%$ of the total population). The final sample size was 554 ( $89.93 \%$ response rate), 38 households refusing to participate and 24 returning incomplete questionnaires. A token incentive payment of USD 2.8 was provided to the participants who agree to take the questionnaire. All surveys were voluntarily conducted, and respondents were free to refuse the survey without any justification. The household heads or their spouses who were highly involved in the decision making of agricultural production and expenditure were assumed to be the decision makers in the adoption preference studies. Among the survey respondents, 385 households cultivated grain crops (wheat and maize) and 169 cash crops (oilseed crops, vegetables, and Chinese herbs). The surveyed sample matched the share of grain and cash crops across the sample district in the study areas. The numbers of grain and cash crop farmers in four sample sites are summarized in Table 1, showing that Linxia and Pingliang have more cash crop farmers compared to Zhangye and Wuwei.

Table 1. The summary of cultivated areas and sample sizes in four study sites.

\begin{tabular}{ccccc|cc}
\hline \multicolumn{3}{c}{ Share of Cultivated Area } & \multicolumn{2}{c}{ Survey Samples (554) } \\
\hline & Grain & Oilseed & Vegetables & Herbs & Grain & with Cash Crops \\
\hline Zhangye & $73.76 \%$ & $10.59 \%$ & $6.24 \%$ & $5.32 \%$ & 103 & 37 \\
Wuwei & $60.29 \%$ & $9.77 \%$ & $17.15 \%$ & $4.37 \%$ & 96 & 28 \\
Linxia & $79.97 \%$ & $8.81 \%$ & $8.24 \%$ & $2.50 \%$ & 108 & 69 \\
Pingliang & $83.51 \%$ & $9.10 \%$ & $5.42 \%$ & $0.92 \%$ & 58 & 55 \\
\hline
\end{tabular}

\subsection{Survey Design}

The survey questionnaire was designed to obtain the perceived importance of SAPs associated with their likelihood of adoption by using the method of best-worst scaling (BWS). The BWS approach is a preference elicitation technique developed by Finn and Louviere [18], in which respondents are invited to choose the best (or most preferred) and the worst (or least preferred) items from a series of choice sets [19]. BWS has been shown to better differentiate amongst objects perceived to be of similar importance over alternative rating and direct ranking methods [14], and is widely used in several disciplines, including agricultural environment [12,14,19], health [20], and marketing [21].

The questionnaire surveyed the socio-demographic characteristics of respondents (i.e., age, gender, educational level, family size) and income, sources of income, farm practices, and attitude towards new farming practices or technologies and government policies. We ensured the BWS choice questions in the last section would measure the relative importance each farmer gives to each of the practices. The proposed nine practices were based on literature reviews $[4,6]$ and group discussions with experts in agriculture and representative farmers during the pre-survey. To ensure the respondents had a basic familiarity with the proposed practices, farmers were provided with detailed explanations of each practice before the questions (Table 2). 
Table 2. List of sustainable agriculture practices (SAPs) used in the best-worst scaling (BWS) choice sets.

\begin{tabular}{|c|c|c|c|c|c|c|}
\hline & \multicolumn{6}{|c|}{ Description } \\
\hline & \multicolumn{6}{|c|}{ Conservation tillage: } \\
\hline \multirow{2}{*}{\multicolumn{7}{|c|}{$\begin{array}{l}\text { Long-term fallow (1-3 years) to minimize the frequency or intensity of tillage opera } \\
\text { resources (Fallow) (1) } \\
\text { Return crop residues to the field (Return crop residues) (7) }\end{array}$}} \\
\hline & & & & & & \\
\hline \multicolumn{7}{|c|}{ Reduce chemical input } \\
\hline \multicolumn{7}{|c|}{$\begin{array}{l}\text { Use organic fertilizers to replace chemical fertilizers (Organic fertili } \\
\text { Apply biochar as a substitute for chemical fertilizers (Biochar) } \\
\text { Cut off } 50 \% \text { use of chemical fertilizers and pesticides (Reduce } 50 \% \text { che }\end{array}$} \\
\hline \multicolumn{7}{|c|}{ Use of cover crops } \\
\hline \multicolumn{7}{|c|}{$\begin{array}{l}\text { Cover crops rotated with current crops (Cover crop rotation) ( } \\
\text { Cover crops intercropped with current crops (Cover crop intercropp } \\
\text { Plant cover crops in marginal farmland (Cover crops in marginal la }\end{array}$} \\
\hline \multicolumn{7}{|c|}{ Agricultural water-saving } \\
\hline \multicolumn{7}{|c|}{ Improve irrigation practices for sustainable water management (Improve irrig } \\
\hline \multirow{2}{*}{\multicolumn{7}{|c|}{$\begin{array}{l}\text { Note: The numbers between parentheses refer to Table } 3 . \\
\text { Table 3. Balanced incomplete block design (BIBD). }\end{array}$}} \\
\hline & & & & & & \\
\hline \multicolumn{7}{|c|}{ Choice Set No. Item No. } \\
\hline 1 & 1 & 2 & 5 & 7 & 8 & 9 \\
\hline 2 & 1 & 3 & 4 & 7 & 8 & 9 \\
\hline 3 & 2 & 3 & 5 & 6 & 7 & 9 \\
\hline 4 & 3 & 4 & 5 & 6 & 7 & 8 \\
\hline 5 & 1 & 2 & 3 & 4 & 6 & 9 \\
\hline 6 & 1 & 2 & 4 & 5 & 6 & 8 \\
\hline 7 & 1 & 2 & 3 & 4 & 5 & 7 \\
\hline 8 & 1 & 2 & 3 & 6 & 7 & 8 \\
\hline 9 & 2 & 3 & 4 & 5 & 8 & 9 \\
\hline 10 & 1 & 3 & 5 & 6 & 8 & 9 \\
\hline 11 & 1 & 4 & 5 & 6 & 7 & 9 \\
\hline 12 & 2 & 4 & 6 & 7 & 8 & 9 \\
\hline
\end{tabular}

The practices fall into four categories: (1) conservation tillage: long-term fallow (1-3 years) and return crop residues to the field are practices for minimizing the frequency or intensity of tillage operations and retaining more cover of crop residues on the soil surface. (2) Reduce chemical input: three practices of using organic fertilizers, biochar, and cutting $50 \%$ of chemical fertilizers used are provided for reducing the total amount of chemical fertilizers and pesticides applied, thus helping to reduce environmental contamination. Biochar is proposed as a new type of compound fertilizer to improve crop productivity and reduce greenhouse gas emissions. (3) Use of cover crops: three alternatives for cover crop rotation, intercropping, and planting in marginal land were introduced for increasing vegetation cover to protect the soil against raindrops and provide an additional source of organic matter. (4) Agricultural water-saving: applying water-saving measures for sustainable water use. Only the practice of long-term fallow was clarified with a 1-3-year adoption period, and the rest of the proposed practices were considered as regular techniques that could be applied in farm work.

In the "classic" case of BWS, an "object case" was used to identify which SAPs farmers "most" or "least" preferred. Following Louviere et al. [22] and Dumbrell et al. [16], we employed a balanced incomplete block design method (BIBD) and obtained 12 choice sets. One choice set contains six practices (Figure 3). Table 3 depicts the full BIBD experimental design. Farmers were invited to choose the best (or most likely to adopt) and worst (or least likely to adopt) practices in each choice set. 


\begin{tabular}{ccc}
\hline Most Prefer & Sustainable Agriculture Practices & Least Prefer \\
\hline$\square$ & Long-term fallow period conserve soil resource (1-3 years) & $\square$ \\
$\square$ & Apply biochar as a substitute for chemical fertilizers & $\square$ \\
$\square$ & Cover crop rotation & $\square$ \\
$\square$ & Return crop residues to the field & $\square$ \\
$\square$ & Improve irrigation practices for sustainable water management & $\square$ \\
$\square$ & Use organic fertilizers to replace chemical fertilizers & $\square$ \\
\hline
\end{tabular}

Figure 3. Sample of BWS questions.

\subsection{Data Analysis}

The process of choosing the best and worst alternatives is described as discrete choice behavior, which is consistent with the random utility theory [22]. We assumed that the respondents would make errors, but when choosing repeatedly, their choice frequencies indicated how much they valued the alternatives under consideration [23]. The pair of attributes chosen by the respondent represents the maximum difference in the underlying, latent scale of the perceived importance of attributes.

In this case, the utility of the difference $(\mathrm{U})$ between the best and worst attributes is comprised of an observable, deterministic component $(v)$ and an unobservable error component $(\varepsilon)$ [19]. The deterministic component $(v)$ can be estimated by the indicator variables of the $i$ attributes and interactions between the $i$ attributes and $j$ independent variables on the farm and the climatic characteristics. The interaction effects allow us to understand how farm and climatic characteristics influence farmers' preferences for the proposed SAPs. The equations to be estimated are:

$$
\begin{gathered}
\mathrm{U}=v+\varepsilon=\beta_{0}+\sum_{i=1}^{9} \beta_{i} x_{i}+\varepsilon, \\
\mathrm{U}=v+\varepsilon=\beta_{0}+\sum_{i=1}^{9} \beta_{i} x_{i}+\sum_{\substack{i=1 \\
j=1}}^{9} \beta_{j} x_{i} * I N T_{j}+\varepsilon,
\end{gathered}
$$

where $v$ denotes the deterministic component of utility, $\beta_{0}, \beta_{i}$ and $\beta_{j}$ are coefficients, $x_{i}, i=1, \ldots, 9$ denotes the attributes, $I N T_{j}$ represents the independent variables selected to interact with the attributes, and $\varepsilon$ is the random error term.

This study assumed a sequential decision process with the best choice being followed by the worst choice, as proposed by Glenk et al. [14]. Thus, the sequential conditional logit model was selected as it depicts the choice probabilities with each practice as a sequence of best-worst choices. Based on these assumptions, using a conditional logit model to estimate the possibility of choosing practice $k$ as the best (most likely to adopt) practice in choice set $X$ is:

$$
\operatorname{Prob}(k=b e s t)=\frac{\exp \left(\beta v_{k}\right)}{\sum_{i \in X} \exp \left(\beta v_{i}\right)} .
$$

Respectively, the probability of choosing practice $k^{\prime}$ as the worst (least likely to adopt) practice among the remaining practices in choice set $X$ is given by:

$$
\operatorname{Prob}\left(k^{\prime}=\text { worst }\right)=\frac{\exp \left(-\beta v_{k^{\prime}}\right)}{\sum_{i^{\prime} \in X} \exp \left(-\beta v_{i^{\prime}}\right)} .
$$

The probability of choosing $k$ as the best and $k^{\prime}$ as the worst alternatives is expressed as:

$$
\operatorname{Prob}\left(k=\text { best } \cap k^{\prime}=\text { worst }\right)=\frac{\exp \beta\left(v_{k}-v_{k^{\prime}}\right)}{\sum_{\substack{i, i^{\prime} \in X \\ i \neq i^{\prime}}} \exp \beta\left(v_{i}-v_{i^{\prime}}\right)} .
$$


Each estimated utility (coefficient) is frequently converted into a share of preference based on the forecasted probability of each attribute, which is defined as:

$$
\text { Share }_{k}=\frac{e^{\beta_{k}}}{\sum_{i=1}^{9} e^{\beta_{i}}} .
$$

The shares of importance for the given attributes relative to the attribute ranked as the least important is normalized to zero [24]. These shares of preferences are estimated on a ratio scale and their sum equals 1 ; they thus indicate the relative importance respondents place on the attributes.

\section{Results}

\subsection{Descriptive Statistics}

Descriptive statistics for the groups of grain and cash crop farmers are presented in Table 4. Female respondents made up $23 \%$ and $18 \%$ of the grain and cash crop farmers, respectively. Furthermore, farmers' average ages were 51.82 and 53.88 years, and average education levels 7.88 and 7.65 years, respectively. The agricultural labor inputs were low, namely 2.30 persons in grain farms and 2.34 persons in cash crop farms. The average farm sizes in both groups were below 1 hectare. The cash crop farmers earned higher incomes for larger farm sizes than grain farmers. More grain farmers (0.35) raised livestock (sheep, goat, cattle, or pig) than cash crop farmers (0.22). On the other hand, the precipitation of cash crop farms (323.14) was higher than that of grain farms (264.31).

Table 4. Basic information among groups.

\begin{tabular}{|c|c|c|c|c|}
\hline & \multicolumn{2}{|c|}{ Grain (385) } & \multicolumn{2}{|c|}{ with Cash Crops (169) } \\
\hline & Mean & Std. Dev. & Mean & Std. Dev. \\
\hline Gender $($ male $=0$, female $=1)$ & 0.23 & 0.42 & 0.18 & 0.39 \\
\hline Age (years) * & 51.82 & 10.22 & 53.88 & 9.77 \\
\hline Education (year) & 7.88 & 3.69 & 7.65 & 3.65 \\
\hline Agricultural labor (number of person) & 2.30 & 1.04 & 2.34 & 1.13 \\
\hline Farm size $(1 \mathrm{mu}=0.0667$ hectare $)$ & 11.78 & 11.35 & 13.20 & 12.84 \\
\hline Household income $(10,000$ yuan $)$ * & 5.14 & 3.90 & 5.90 & 5.03 \\
\hline Livestock $($ yes $=1$, no $=0) *$ & 0.35 & 0.48 & 0.22 & 0.41 \\
\hline Precipitation $(\mathrm{mm}) * *$ & 264.31 & 144.36 & 323.14 & 133.42 \\
\hline
\end{tabular}

\subsection{Relative Importance of SAPS}

Conditional logit estimations based on Equations (1), (5) and (6) were performed using R software (version 3.2.3, R Core, 2015). The results are shown in Table 5. The coefficients were converted into preference shares on a ratio scale to provide more intuitive details on the relative importance of attributes for grain and cash crop farmers.

The results indicate that using more organic fertilizers to replace chemical fertilizers was the most preferred practice, with the highest shares of $26.7 \%$ and $26.2 \%$ for grain and cash crop farmers, respectively. The next highest share was improving irrigation practices, with the preference share being higher for grain farmers $(22.2 \%)$ than cash crop farmers $(18.2 \%)$. Three practices related to cover crop applications ranked next in the relative importance of preference. It is worth noting that cash crop farmers placed higher importance on cover crop rotation (14.1\%) and intercropping (13.9\%) than grain farmers, indicating stronger preferences for applications associated with cover crops by cash crop farmers. Compared with the highest preference share of using organic fertilizers, cover crop-related practices perceived approximately half the importance of using organic fertilizers. This result indicates that, despite the roles of legume and non-legume cover crops in reducing soil erosion, conserving soil moisture, and fixing atmospheric nitrogen, the adoption of these practices is still hindered by 
concerns over high seed cost and extra-economic constraints [25]. Overall, the practice of long-term fallow was the least likely to be adopted, with proportions of $2.4 \%$ and $3.1 \%$ for grain and cash crop farmers, respectively. Additionally, the practice of returning crop residues to the field was selected as the second least likely to be adopted by both grain $(4.8 \%)$ and cash crop $(4.5 \%)$ farmers.

Table 5. Relative importance of SAPs among groups.

\begin{tabular}{ccccccc}
\hline \multirow{2}{*}{ Practices } & \multicolumn{3}{c}{ Grain } & \multicolumn{3}{c}{ with Cash Crops } \\
\cline { 2 - 6 } & Coef. & Std. Error & Share & Coef. & Std. Error & Share \\
\hline Organic fertilizer & $2.391^{* * *}$ & 0.047 & $26.7 \%$ & $2.138^{* * *}$ & 0.070 & $26.2 \%$ \\
Improve irrigation practices & $2.206^{* * *}$ & 0.047 & $22.2 \%$ & $1.776^{* * *}$ & 0.070 & $18.2 \%$ \\
Cover crop rotation & $1^{*} .567^{* * *}$ & 0.463 & $11.7 \%$ & $1.520^{* * *}$ & 0.070 & $14.1 \%$ \\
Cover crop intercropping & $1.501^{* * *}$ & 0.462 & $11.0 \%$ & $1.505^{* * *}$ & 0.070 & $13.9 \%$ \\
Cover crops in marginal land & $1.236^{* * *}$ & 0.046 & $8.4 \%$ & $1.062^{* * *}$ & 0.068 & $8.9 \%$ \\
Biochar & $1^{* * 053^{* *}}$ & 0.045 & $7.1 \%$ & $0.679^{* * *}$ & 0.066 & $6.1 \%$ \\
Reduce 50\% chemicals & $0.852^{* * *}$ & 0.044 & $5.7 \%$ & $0.508^{* * *}$ & 0.065 & $5.1 \%$ \\
Return crop residues & $0.676^{* * *}$ & 0.043 & $4.8 \%$ & $0.367^{* * *}$ & 0.064 & $4.5 \%$ \\
Fallow & fixed & - & $2.4 \%$ & fixed & - & $3.1 \%$ \\
\hline
\end{tabular}

Note: ${ }^{* * *}$ indicates significance at the 0.001 level.

\subsection{Adoption Preferences of SAPs with Interaction Effects}

For a better understanding of how farm and climatic characteristics influence the decision making related to SAPs, multiple models were run to analyze adoption preferences with interaction effects based on Equations (2)-(5). The results in Table 6 indicate the adoption preferences of SAPs in relation to household income, livestock status, and precipitation. The household income indicates farmers' financial situation to improve farming practices. As one major source of income, livestock can utilize leguminous cover crops as forage and produce organic manure [26]. The climatic feature of precipitation is critical not only because it effects the growth of crops and vegetation cover but also because it determines the water content and water-holding capacity of the soil for crop residue treatments [27]. Therefore, these three variables had been selected to interact with the nine SAPs for grain and cash crop farmers. Taking into consideration these research objectives, using the conditional logit model to estimate the interaction effects was better than the latent class model in illustrating the impact of selected variables on the adoption preferences in this study. Both models fit the data well based on McFadden's pseudo $\mathrm{R}^{2}$ measures [24]. All parameter estimates are relative to the reference item, where positive coefficient values indicate that farmers are more likely to adopt a practice and negative values suggest the practice is less likely to be adopted compared with fallow.

When considering interaction effects, grain farmers were more likely to improve irrigation practices, use more organic fertilizers or biochar to replace chemical fertilizers, resort to cover crop rotation and intercropping and reduce the use of chemical inputs by $50 \%$. Furthermore, there were no significant differences in planting cover crops in marginal land. Grain farmers were also less likely to return crop residues to the field. Household incomes, livestock, and precipitation interacted significantly with some practices, especially those related to household income and livestock. Farmers with higher household incomes were more likely to adopt cover crop rotation and return crop residues to the field, as these are practices that require extra costs, such as seeds and machinery costs. Grain farmers with livestock were more likely to replace chemical fertilizers with organic ones, improve irrigation practices, and reduce the use of chemical fertilizers and pesticides by $50 \%$, but less likely to adopt cover crop intercropping. When precipitation increases, grain farmers were more likely to adopt cover crop-related practices and use more organic fertilizers. 
Table 6. Conditional logit model estimates for the interaction effects of grain and cash crop farmers.

\begin{tabular}{|c|c|c|c|c|}
\hline \multirow{2}{*}{ Practice } & \multicolumn{2}{|c|}{ Grain } & \multicolumn{2}{|c|}{ with Cash Crops } \\
\hline & Coef. & Std. Error & Coef. & Std. Error \\
\hline Organic fertilizers & $1.787^{* * *}$ & 0.284 & $1.337 * * *$ & 0.449 \\
\hline Improve irrigation practices & $2.395^{* * *}$ & 0.324 & 0.859 & 0.524 \\
\hline Cover crop rotation & $0.670^{* * *}$ & 0.226 & -0.124 & 0.370 \\
\hline Cover crop intercropping & $0.746^{* * *}$ & 0.206 & 0.221 & 0.337 \\
\hline Cover crops in marginal land & 0.210 & 0.246 & 0.338 & 0.404 \\
\hline Biochar & $0.900 * * *$ & 0.155 & 0.313 & 0.293 \\
\hline Reduce $50 \%$ chemicals & $0.355^{*}$ & 0.197 & $-2.07^{* * *}$ & 0.351 \\
\hline Return crop residues & $-0.428 *$ & 0.255 & 0.249 & 0.400 \\
\hline Fallow & fixed & - & - & - \\
\hline \multicolumn{5}{|l|}{ Interaction effects } \\
\hline Organic fertilizers $\times$ Household income & $-0.038^{* *}$ & 0.018 & $0.090 * * *$ & 0.023 \\
\hline Improve irrigation practices $\times$ Household income & 0.022 & 0.027 & $0.141^{* * *}$ & 0.023 \\
\hline Cover crop rotation $\times$ Household income & $0.062 * * *$ & 0.017 & $0.110 * * *$ & 0.021 \\
\hline Cover crops in marginal land $\times$ Household income & -0.020 & 0.018 & $0.081^{* * *}$ & 0.020 \\
\hline Reduce $50 \%$ chemicals $\times$ Household income & -0.011 & 0.017 & $0.127^{* * *}$ & 0.019 \\
\hline Return crop residues $\times$ Household income & $0.054^{* * *}$ & 0.020 & $0.131^{* * *}$ & 0.021 \\
\hline Organic fertilizers $\times$ livestock & $0.337^{* *}$ & 0.170 & 0.421 & 0.285 \\
\hline Improve irrigation practices $\times$ livestock & $0.905^{* * *}$ & 0.192 & -0.321 & 0.265 \\
\hline Cover crop rotation $\times$ livestock & -0.045 & 0.162 & $0.830 * * *$ & 0.240 \\
\hline Cover crop intercropping $\times$ livestock & $-0.267 *$ & 0.155 & $0.577 *$ & 0.239 \\
\hline Reduce $50 \%$ chemicals $\times$ livestock & $0.387^{* * *}$ & 0.140 & $1.153^{* * *}$ & 0.255 \\
\hline Organic fertilizers $\times$ Precipitation & $0.002^{* * *}$ & 0.001 & 0.001 & 0.001 \\
\hline Cover crop rotation $\times$ Precipitation & $0.002 * * *$ & 0.001 & 0.001 & 0.001 \\
\hline Cover crop intercropping $\times$ Precipitation & $0.003^{* * *}$ & 0.000 & $0.003^{* * *}$ & 0.001 \\
\hline Cover crops in marginal land $\times$ Precipitation & $0.002 * * *$ & 0.001 & $0.002 * * *$ & 0.001 \\
\hline Reduce $50 \%$ chemicals $\times$ Precipitation & 0.000 & 0.000 & $0.002 * * *$ & 0.001 \\
\hline Log-likelihood & \multicolumn{2}{|c|}{-9938.1} & \multicolumn{2}{|c|}{-4207.1} \\
\hline Observations & \multicolumn{2}{|c|}{4620} & \multicolumn{2}{|c|}{2028} \\
\hline McFadden's pseudo $\mathrm{R}^{2}$ & \multicolumn{2}{|c|}{0.435} & \multicolumn{2}{|c|}{0.379} \\
\hline
\end{tabular}

Cash crop farmers were more likely to use more organic fertilizers instead of chemical ones and less likely to reduce the use of chemical fertilizers and pesticides by $50 \%$. Household income had significant positive effects on using organic fertilizers, cover crop rotation and intercropping, and planting cover crops in marginal land. Like the estimations for grain farmers, cash crop farmers with higher household incomes were also more likely to return crop residues to the field. Conversely, cash crop farmers with livestock tended to adopt cover crops related practices. As with grain farmers, cash crop farmers with livestock were also more likely to reduce the use of chemical fertilizers and pesticides by $50 \%$. Higher precipitation had a positive effect on cover crop intercropping and reducing the use of chemical fertilizers and pesticides by $50 \%$.

Overall, farmers were more open to organic fertilizers and responded positively to water deficit problems, such as by improving irrigation practices and increasing the vegetation cover. The significant coefficients of the interactions between household income and precipitation with the SAPs indicate that financial and climatic considerations were considered in the decision making for SAPs. As an income source, livestock was also considered important to organic manure production, which can provide a substitute for chemical fertilizers.

\section{Discussion}

To identify reasonable measures to mitigate soil degradation and maintain agricultural sustainability in the arid and semiarid areas in northwest China, this study used the BWS approach to explore the adoption preferences for SAPs and how farm and climatic characteristics affect decision 
making. Farmers were shown to prefer using organic fertilizers to replace chemical fertilizers other than planting cover crops, returning crop residues to the field, and applying new fertilizers such as biochar. One key measure of the "Achieving zero growth in the use of chemical fertilizer and pesticides by 2020" policy launched by the Ministry of Agriculture in China (MOA) is reducing the use of chemical fertilizers by $50 \%$ and using organic fertilizers instead for cash crops, which has been promoted in the northwest ecological fragile district of Gansu since 2015 [27]. Many farmers are familiar with this practice and recognize its benefits. However, compared with the cost of recycling straw and stubble to produce organic compost, organic fertilizers proved to reduce costs and fertilizer inputs for the dryland farming of wheat and corn [28]. Particularly, due to dryland soil moisture deficits, straw treatments, such as chopping and smashing, are required for the decomposition of straw, thus adding machinery costs and labor inputs [29]. The interaction effects further indicated that households with a higher income preferred to return crop residues to the field. Therefore, a low-income level and extra processing expenditures could pose constraints for crop residues being returned to the field in impoverished and semiarid regions in China.

Based on our results, although grain and cash crop farmers were most likely to adopt organic fertilizers, there is less agreement over reducing the use of chemical fertilizers and pesticides by $50 \%$ among cash crop farmers. This is in line with Nolan et al. [2] and Fan et al. [13] in that, in many lower-income districts and countries, the profits from cash crops of vegetables, oilseed, and fruits commonly make up more than $50 \%$ of the household income, while also playing an important role in increasing annual income by over $30 \%$. Therefore, the pursuit of production and high income impedes farmers from reducing chemical inputs, particularly cash crop farmers, who generally use more chemical fertilizers and pesticides. Based on Table 6, grain farmers were more supportive of reducing the use of chemicals by $50 \%$.

Grain farmers stated a stronger preference for improving irrigation practices than cash crop farmers. Indeed, many grain farmers struggle with water deficit problems for self-sufficient and agricultural production. This result was amplified by the positive effects of precipitation in the interaction analysis. The interaction effects indicated that, along with favoring irrigation practices, cash crop farmers with higher household incomes also prefer cover crop rotation and intercropping. Data from the survey showed that cash crops account for $15 \%$ to $25 \%$ of the cultivated areas and commonly include legumes such as field pea (Pisum sativum L.) and lucerne (Medicago sativa L.), and oilseed crops such as linseed (Linum usitatissimum L.) and rapeseed (Brassica napus L.), which are also considered as cover crops. Therefore, as the current users and adopters of cover crops, cash crop farmers preferred to continue these practices. From a survey of Scottish dairy farmers, Glenk et al. [14] also found that current adoption has a significant positive impact on the probability to choose a practice as "best." Additionally, cover crop rotation had a higher preference share than intercropping with cover crops. This could be explained by the concerns over water deficits and the probability of soil water depletion that can negatively affect crop yields when intercropping with cover crops.

It is worth noting that the results of the interaction effects between cover crops with livestock contradicted our expectation that planting cover crops would provide forage for livestock, thus being favorable to farmers. However, because only less than $10 \%$ of the cultivated land being devoted to legumes and cover crops for forage, the above-ground biomass of dryland tolerant legume or non-legume cover crops could not meet the demand of forage [26]. Furthermore, instead of using cover crops as forage, crop residues, and byproducts, such as corn straws, were the primary sources of forage for livestock. Therefore, livestock did not interact with cover crop-related practices for grain farmers. This inference is also supported by the low preference share of returning crop residues (4.8\%) to the field. However, livestock had significant positive effects on reducing the use of chemical fertilizers and pesticides by $50 \%$ for both grain and cash crop farmers. The organic manure produced by livestock has been considered an important substitute for chemical fertilizers.

This study provides novel insights into comprehensive policy design for SAPs in the arid and semiarid northwest areas of China. China has had a long history of policies designed to guide the 
agricultural sector for improving the rural environment and boosting the productive capacity and agricultural income. However, large-scale attempts to restore degraded and vulnerable farmland need to consider the local environment, particularly in impoverished regions with water-use deficits [9]. Otherwise, the same conservation project with the same level of standard compensation throughout the study areas would lead to lower participation and slower progress in the promotion of the conservation programs [30].

The comparisons of climatic and farm characteristics between four study sites indicate that Linxia and Pingliang obtain more precipitation and have more cash crop farmers than Zhangye and Wuwei. Taking into consideration the district differences, practices relating to organic fertilizer and cover crops might be plausible suggestions to the cash crop farmers in the semiarid areas with a certain level of rainfall. Furthermore, maize is often grown in crop-livestock farming systems in northwest China [29], so integrating maize rotated with leguminous cover crops into the system could be favorable and beneficial for farmers, as both maize straw and leguminous forages can be fed to livestock and converted back to the soil as organic manure.

One critical consideration in this study is to address the awareness of the perceived importance of different SAPs by farmers and the need for diverse SAPs at the farm level. The interaction findings revealed that, in addition to economic conditions, the cropping differences and climatic features influenced decision making in terms of adoption preferences. Therefore, diversifying SAP combinations by considering diverse cropping and geographic factors would be beneficial for soil conservation management and wide application $[12,16]$. For example, organic fertilizers and cover crops should be specifically targeted to cash crop farmers, based on the positive correlations of cover crops and livestock in the interaction analysis. The practices challenged by extra economic input are more likely to have a more limited adoption and therefore require greater interventions, including incentive payments or technical advice and support.

The price subsidy mechanism has been proved to be a necessary and effective technical support to stimulate farm households to apply SAPs in the resource-poor northwest China $[6,13,27]$. The incentive levels varied greatly in different regions with practices of crop rotation, managed fallow, and green manure cover crops planting. The government provides a payment of 1091 yuan per hectare to farmers who convert arable lands into forests or permanent pastures on sloped cultivated land in the upper reaches of the Yellow River basins [6]. Consistent with former research [9], this study further amplified cost as an important factor influencing farmers' acceptance of the SAPs. Therefore, high compensation could be required for the implementation of long-term fallow and return crop residues to the field. In contrast, relatively low incentive payments for the use of organic fertilizers and water-saving practices could be accepted by the farmers in arid and semiarid regions.

\section{Conclusions}

This study provides useful implications for farmers in the arid and semiarid areas of northwest China in terms of SAPs and considering cropping differences and climatic conditions. The results show that balancing crop yield and sustainable development influence farmers' decision making. Grain farms within lower precipitation level areas favored replacing chemicals with organic fertilizers and the improvement of irrigation practices. In addition to these two practices, cash crop farmers also selected cover crop-related practices, which require a certain level of rainfall. The different perceived importance of these practices suggests new combinations or packages for soil conservation programs during the adjustment of the cropping structure in Gansu. As such, using BWS and considering social-economic and climatic characteristics in identifying the types of farming systems and numbers of conservation practices can help in the early stages of policy design and for determining adequate levels of economic incentives.

Based on the current findings, some policy implications are suggested. Firstly, a technical cost reduction for replacing chemical fertilizers with organic fertilizers and water-saving practices by government subsidies would be efficient to improve the likelihood of adoption. Secondly, incentive 
programs should focus on the adoption period of the cover crops. Thirdly, rotation or intercropping is an alternate method for the promotion of cover crops in the intensive farming areas. Nevertheless, for districts like Zhangye and Wuwei, with extremely limited water resources, the evaluation of trade-off decisions between traditional and sustainable agricultural practices by farmers is indispensable to the implementation of SAPs.

This study selected geographically separated areas with different levels of precipitation, which enables us to compare the responses for different social-economic and agroclimatic conditions. However, there is no guarantee that a practice perceived as the most likely to be adopted will indeed lead to its future application due to the wider range of constraints and obstacles, such as unpredictable climatic changes and natural disaster risks, which can result in production and income fluctuations. Hence, an in-depth investigation of cropping systems with detailed agricultural inputs and geoclimatic factors with a larger sample size may improve our evaluation. To strengthen and extend the range of the study, the adoption constraints of risk perception and attitude and the spatial heterogeneity of different geo-climatic sites could be considered in future research.

Author Contributions: Conceptualization, Y.N., C.Y., and H.C.; methodology, Y.N. and H.C.; investigation, Y.N., X.Y., and J.R.; writing-original draft preparation, Y.N.; writing—review and editing, H.C. and X.Y.; supervision, H.C.; funding acquisition, C.Y. All authors have read and agreed to the published version of the manuscript.

Funding: This research was funded by China Agriculture Research System-Green Manure (CARS-22-G-25).

Acknowledgments: We would like to thank the editor and the anonymous reviewers for their helpful comments and suggestions.

Conflicts of Interest: The authors declare no conflict of interest.

\section{References}

1. Lal, R. Tillage effects on soil degradation, soil resilience, soil quality, and sustainability. Soil Tillage Res. 1993, 27, 1-8. [CrossRef]

2. Nolan, S.; Unkovich, M.; Yuying, S.; Lingling, L.; Bellotti, W. Farming systems of the Loess Plateau, Gansu Province, China. Agric. Ecosyst. Environ. 2008, 124, 13-23. [CrossRef]

3. Peng, D.; Zhou, T. Why was the arid and semiarid northwest China getting wetter in the recent decades? J. Geophys. Res. Atmos. 2017, 122, 9060-9075. [CrossRef]

4. Li, L.-L.; Huang, G.-B.; Zhang, R.-Z.; Bill, B.; Guangdi, L.; Kwong, Y.C. Benefits of conservation agriculture on soil and water conservation and its progress in China. Agric. Sci. China 2011, 10, 850-859. [CrossRef]

5. Poverty Reduction and Economic Management Department. China_From Poor Areas to Poor People. China's Evolving Poverty Reduction Agenda-An Assessment of Poverty and Inequality; Report No. 47349-CN; East Asia and Pacific Region, The World Bank: Washington, DC, USA, 2009; pp. 1-261.

6. Wen, X.; Zhen, L. Soil erosion control practices in the Chinese Loess Plateau: A systematic review. Environ. Dev. 2020, 34, 100493. [CrossRef]

7. Gansu Provincial Bureau of Statistics. Gansu Statistical Yearbook 2018; China Statistics Press: Beijing, China; pp. 278-288.

8. Giller, K.E.; Corbeels, M.; Nyamangara, J.; Triomphe, B.; Affholder, F.; Scopel, E.; Tittonell, P. A research agenda to explore the role of conservation agriculture in African smallholder farming systems. Field Crops Res. 2011, 124, 468-472. [CrossRef]

9. Luo, L.; Qin, L.; Wang, Y.; Wang, Q. Environmentally-friendly agricultural practices and their acceptance by smallholder farmers in China-A case study in Xinxiang County, Henan Province. Sci. Total Environ. 2016, 571, 737-743. [CrossRef]

10. Corbeels, M.; de Graaff, J.; Ndah, T.H.; Penot, E.; Baudron, F.; Naudin, K.; Andrieu, N.; Chirat, G.; Schuler, J.; Nyagumbo, I.; et al. Understanding the impact and adoption of conservation agriculture in Africa: A multi-scale analysis. Agric. Ecosyst. Environ. 2014, 187, 155-170. [CrossRef]

11. Tong, Q.; Zhang, L.; Zhang, J. Evaluation of GHG Mitigation measures in rice cropping and effects of farmer's characteristics: Evidence from Hubei, China. Sustainability 2017, 9, 1066. [CrossRef] 
12. Jones, A.K.; Jones, D.L.; Edwards-Jones, G.; Cross, P. Informing decision making in agricultural greenhouse gas mitigation policy: A best-worst Scaling survey of expert and farmer opinion in the sheep industry. Environ. Sci. Policy 2013, 29, 46-56. [CrossRef]

13. Fan, L.; Niu, H.; Yang, X.; Qin, W.; Bento, C.P.M.; Ritsema, C.J.; Geissen, V. Factors affecting farmers' behaviour in pesticide use: Insights from a field study in northern China. Sci. Total Environ. 2015, 537, 360-368. [CrossRef] [PubMed]

14. Glenk, K.; Eory, V.; Colombo, S.; Barnes, A. Adoption of greenhouse gas mitigation in agriculture: An analysis of dairy farmers' perceptions and adoption behaviour. Ecol. Econ. 2014, 108, 49-58. [CrossRef]

15. Yue, D.; Xu, X.; Li, Z.; Hui, C.; Li, W.; Yang, H.; Ge, J. Spatiotemporal analysis of ecological footprint and biological capacity of Gansu, China 1991-2015: Down from the environmental cliff. Ecol. Econ. 2006, 58, 393-406. [CrossRef]

16. Wen, X.; Wu, X.; Gao, M. Spatiotemporal variability of temperature and precipitation in Gansu Province (Northwest China) during 1951-2015. Atmos. Res. 2017, 197, 132-149. [CrossRef]

17. Yao, L.; Zhao, M.; Xu, T. China's Water-Saving Irrigation Management System: Policy, Implementation, and Challenge. Sustainability 2017, 9, 2339.

18. Finn, A.; Louviere, J.J. Determining the appropriate response to evidence of public concern: The case of food safety. J. Public Policy Mark. 1992, 11, 12-25. [CrossRef]

19. Dumbrell, N.P.; Kragt, M.E.; Gibson, F.L. What carbon farming activities are farmers likely to adopt? A best-worst scaling survey. Land Use Policy 2016, 54, 29-37. [CrossRef]

20. Mori, T.; Tsuge, T. Best-worst scaling survey of preferences regarding the adverse effects of tobacco use in China. SSM-Popul. Health 2017, 3, 624-632. [CrossRef]

21. Stanco, M.; Lerro, M.; Marotta, G. Consumers' preferences for wine attributes: A best-worst scaling analysis. Sustainability 2020, 12, 2819. [CrossRef]

22. Louviere, J.J.; Flynn, T.N.; Marley, A.A.J. Best-Worst Scaling: Theory, Methods and Applications; Cambridge University Press: Cambridge, UK, 2015; pp. 16-17.

23. Thurstone, L.L. A law of comparative judgment. Psychol. Rev. 1927, 34, 273-286. [CrossRef]

24. Sackett, H.M.; Shupp, R.; Tonsor, G. Consumer perceptions of sustainable farming practices: A best-worst scenario. Agric. Res. Econ. Rev. 2013, 42, 275-290. [CrossRef]

25. Blackshaw, R.E.; Molnar, L.J.; Moyer, J.R. Suitability of legume cover crop-winter wheat intercrops on the semi-arid Canadian Prairies. Can. J. Plant Sci. 2010, 90, 479-488. [CrossRef]

26. Zhang, W.-S.; Li, F.-M.; Xiong, Y.-C.; Xia, Q. Econometric analysis of the determinants of adoption of raising sheep in folds by farmers in the semiarid Loess Plateau of China. Ecol. Econ. 2012, 74, 145-152. [CrossRef]

27. Shuqin, J.; Fang, Z. Zero growth of chemical fertilizer and pesticide use: China's objectives, progress and challenges. J. Res. Ecol. 2018, 9, 50-58. [CrossRef]

28. Xu, H.; Huang, X.; Zhong, T.; Chen, Z.; Yu, J. Chinese land policies and farmers' adoption of organic fertilizer for saline soils. Land Use Policy 2014, 38, 541-549. [CrossRef]

29. Soon, Y.K.; Lupwayi, N.Z. Straw management in a cold semi-arid region: Impact on soil quality and crop productivity. Field Crops Res. 2012, 139, 39-46. [CrossRef]

30. Cao, S.; Wang, X.; Song, Y.; Chen, L.; Feng, Q. Impacts of the Natural Forest Conservation Program on the livelihoods of residents of Northwestern China: Perceptions of residents affected by the program. Ecol. Econ. 2010, 69, 1454-1462. [CrossRef]

(C) 2020 by the authors. Licensee MDPI, Basel, Switzerland. This article is an open access article distributed under the terms and conditions of the Creative Commons Attribution (CC BY) license (http://creativecommons.org/licenses/by/4.0/). 